\title{
La Argentina kirchnerista: Alcances y límites de una experiencia democrática sobre la distribución del ingreso (2003-2015)
}

\author{
Lucía Trujillo \\ CONICET-Universidad Nacional de La Plata, Buenos Aires, Argentina \\ Email: luciatrujillos@gmail.com
}

\begin{abstract}
Resumen: Este artículo tiene como objetivo ofrecer la reconstrucción de uno de los procesos de "giro a la izquierda" que evidencia un fin de ciclo: el kirchnerismo en Argentina. Para ello se presta atención a los elementos que hicieron posibles avances en el combate a la desigualdad, así como los problemas que la política económica enfrentó. La comprensión de los procesos de la experiencia argentina aportará a un balance sobre los alcances y las limitaciones del kirchnerismo en las políticas de distribución del ingreso.

Palabras clave: Giro a la izquierda, Kirchnerismo, Argentina, democracia, desigualdad del ingreso.
\end{abstract}

\section{The Kirchnerist Argentina: Achievements and Limitations of a Democratic Experience on the Income distribution (2003-2015)}

\begin{abstract}
This article aims to offer the reconstruction of a process related to "Latin America's left turn" This article aims at offering the reconstruction of one of the processes related to "Latin America's left turn" that demonstrates the end of a cycle: The Kirchnerist Government in Argentina. To achieve this purpose, the focus is set on the elements that made possible to make progress in the fight against inequality, as well as the issues faced by economic policy. Understanding the processes of the Argentinian experience will contribute to an assessment on the achievements and limitations of the income distribution policies during this period.

Keywords: Left turn, Kirchnerism, Argentina, democracy, income inequality

\section{AArgentina kirchnerista: Alcances e limites de uma experiência democrática sobre a distribuição de renda (2003-2015)}

Resumo: Este artigo tem como objetivo oferecer a reconstrução de um dos processos do "giro para a esquerda" que evidencia o fim de um ciclo: o kirchnerismo na Argentina. Para isso presta-se atenção aos elementos que fizeram possível os avanços no combate à desigualdade, assim como os problemas que a política económica enfrentou. A compreensão dos processos da experiencia argentina aportará a 
um balance sobre os alcances e as limitações do kirchnerismo nas políticas de distribuição de renda.

Palavras chave: Giro para a esquerda, Kirchnerismo, Argentina, democracia, desigualdade de renda

$* * *$

\section{Introducción}

El actual escenario político de América Latina muestra signos de reversión de algunos de los procesos que habían marcado el "giro a la izquierda" o "marea rosa" ${ }^{1}$. Esta situación reabre el debate sobre los alcancesde las transformaciones progresistas, sus limitaciones y los escenarios actuales en pos de evitar reversiones de los avances y la reorganización de actores capaces de plantear alternativas superadoras. En este contexto, una de las tareas es analizar los alcances de las transformaciones realizadas por los gobiernos progresistas de la región en cuanto a la democracia. Democracia que no se agota en el funcionamiento de procedimientos para la selección de elites gubernamentales sino que alcanzan los modos en los que se integra la sociedad, los patrones de intercambio y la dimensión socio-económica dela democracia plasmada en el resguardo de los derechos sociales y económicos. Si el neoliberalismo había marcado una fuerte restricción del acceso a derechos y desmejorado tanto la situación de los sectores populares, los gobiernos del giro a la izquierda buscaron -en distinta medida y con diferentes estrategias- revertir la situación poniendo, por ejemplo, al Estado en el centro de la coordinación social. Estas acciones gubernamentales no suceden en el vacío sino en contextos económicos afectados por procesos de diferentes escalas (globales, nacionales, locales) y relaciones de fuerzas con otros actores sociales y políticos.

La pregunta por la situación actual de América Latina requiere de un estudio de los procesos políticos capaces de poner en evidencia alcances, limitaciones y nudos problemáticos que aporten a la comprensión de las fases que se cierran como aporte a los diagnósticos de la etapa actual y las posibilidades futuras. En este sentido, este artículo se propone un análisis del proceso político argentino iniciado en 2003 a partir de poner el foco en la dimensión socio-económica de la democracia que apunta a visibilizar las dinámicas en que se distribuyen los lugares y los recursos en una sociedad, los cuales permiten el ejercicio de la ciudadanía. Este aspecto social de la democracia, junto con el aspecto político ligado a las formas de participación y los protagonismos ciudadanos, constituyen claves para comprender las etapas recientes y configurar proyectos que articulen mejoras socioeconómicas para las mayorías con fortalecimiento de los regímenes de participación y ejercicio de la ciudadanía.

El artículo se estructura en tres partes. La primera identifica algunos puntos salientes de las reformas neoliberales. La segunda analiza la dinámi- 
ca socio-económica en los tres gobiernos kirchneristas a los que se dedican respectivas secciones (Néstor Kirchner 2003-2007, Cristina Fernández de Kirchner, 2007-2011 y 2011-2015) poniendo el eje en la dinámica de la distribución personal del ingreso en el contexto de las políticas gubernamentales. Finalmente, en la última sección, se apuntan algunas conclusiones sobre el período y la etapa actual liderada por una alianza de centro-derecha que llevó a la presidencia a Mauricio Macri en diciembre de 2015.

\section{EI neoliberalismo contra la democracia}

Las transformaciones de las últimas décadas del siglo XX sin duda han impactado en la estructuración de la sociedad argentina. Desde mediados de la década del setenta se inició un proceso de progresivo y sostenido desmejoramiento de la situación social que abarcó casi tres décadas y se evidenció en el deterioro en las condiciones de vida, el aumento de la desigualdad, la pobreza y el desempleo. El plan sistemático de la dictadura militar estuvo orientado a reestructurar las bases del patrón de acumulación a partir de una serie de reformas orientadas a liberalizar y desregular la economía (Basualdo, 2006).Estos cambios, que no se revirtieron significativamente bajo la presidencia de Raúl Alfonsín (Schorr y Ortiz, 2006), se consolidaron en la década del noventa donde se alteraron aspectos centrales del modo de acumulación, la estructura productiva, los patrones distributivos, y las instituciones laborales y de protección social así como el régimen político.Durante la presidencia de Carlos Menem, un período de democracia delegativa (Odonnell, 1992), se afectaron mecanismos de integración social de la matriz nacional-popular (Garretón, 2002) a partir de las reformas estructurales que implicaron privatizaciones de las empresas públicas, políticas de liberación comercial, desmantelamiento del sistema público y estatal de protección social y flexibilización del mercado de trabajo (Gerchunoff y Torre, 1996).

Estas medidas afectaron diferentes patrones de integración social. La primacía del mercado orientó la coordinación social y esto tuvo efectos regresivos sobre la situación general de los sectores populares, luego de una primera etapa en que el modelo logró controlar la inflación. Entre las reformas estructurales de los años noventa se destaca la que transformó el sistema previsional en 1993 que creó un nuevo sistema integrado de jubilaciones y pensiones que reemplazaba el sistema puesto en crisis por cuestiones de financiamiento y de organización interna. En efecto, los actores principales del nuevo sistema fueron las Administradoras de Fondos de Jubilaciones y Pensiones -AFJP-, un régimen de capitalización privada liderado por el sector financiero(Bertranou y Bonari, 2005). Además, se aumentó la edad de jubilación que pasó de 55 a 60 años para las mujeres y de 60 a 65 años para los varones, se cambió la manera de computar los salarios y se incrementó de 20 a 30 los años de aportes como requisito para obtener la jubilación. Después de su implementación, en 1994, el sistema previsional evidenció una baja en la cobertura acentuada en los mayores de 65 años (Cetrángolo y Grushka, 2004; Bertranou, Rofman y Grushka, 2003). 
El incremento en las tasas de desocupación y la conflictividad social ascendente motivó la instrumentación de políticas sociales y laborales para atender a la población en situación de desocupación y pobreza. Si bien existieron variados programas de empleo, éstos se caracterizaron por una cobertura acotada, alta rotación y bajos recursos invertidos. Según Golbert (2004) para 1996 existían 31 programas de empleo entre los cuales se destaca, por persistencia y cobertura, el Plan Trabajar. Este plan -que tuvo tres versiones I, II y III- fue utilizado como recurso de negociación ante las incipientes movilizaciones sociales de grupos de desocupados ${ }^{2}$. Desde fines de 1995 y hasta 1999, los Planes trabajar constituyeron la principal política orientada al segmento de la población más vulnerable a partir de una transferencia no remunerativa a cambio de una contraprestación.

Hacia finales de la década la Argentina mostraba un panorama económico dominado por problemas fiscales. El cese del ingreso extraordinario producido por la venta de las empresas estatales y las consecuencias de la reforma previsional, produjeron impactos significativos en el déficit fiscal que conjugados con el incremento del endeudamiento externo generó una situación de agotamiento estructural. En efecto, el éxito del modelo de Convertibilidad residía en la capacidad de respaldar la paridad pesodólar a partir del ingreso de divisas ya sea vía superávit comercial o ingreso de capitales. Sin embargo en la segunda parte de la década la dinámica económica mostró un menguado ingreso de capitales, un incremento del endeudamiento y una fuga de divisas de los actores económicos locales. Esta situación obligó al gobierno a contraer mayor endeudamiento externo tanto para financiar su propio déficit como evitar la cesación de pagos de los privados endeudados en moneda extranjera (Damill, Frenkel y Juvenal, 2003).

El compromiso de garantizar la Convertibilidad por parte de la Alianza UCR-Frepaso, bajo la presidencia de Fernando de la Rúa (1999-2001), hizo que el gobierno tuviera que lidiar con este esquema macroecoenómico marcado por los problemas de una economía estancada, déficit fiscal y sobreendeudamiento. El acuerdo con el Fondo Monetario Internacional como "Blindaje" para obtener fondos y así evitar una cesación de pagos y el intento del Megacanjede bonos de la deuda en 2001 fueron muestras de lo acuciante de la situación (Damill, Frenkel y Maurizio, 2003).

La actividad económica que venía dando muestras de dificultades acentuadas desde 1998 confirmó su tendencia recesiva en 2001, el desempeño en los indicadores sociales y laborales así lo evidenció ${ }^{3}$. La política social de la Alianza registró una merma en la asignación de Planes Trabajar y la aparición de otros programas de transferencias como el Programa de Emergencia Laboral, mientras que en la provincia de Buenos Aires se amplió el programa Barrios Bonaerenses”“

Los acontecimientos suscitados en diciembre de 2001, que incluyeron la renuncia del ministro de economía primero, y del presidente de la república, después, marcaron la salida política a la crisis económica a favor 
del proyecto devaluacionista, luego de que se decretara el default de la deuda pública. Después de una sucesión de presidentes nombrados por la Asamblea Legislativa y sus respectivas renuncias asumió el senador por la provincia de Buenos Aires (y exgobernador) Eduardo Duhalde.

El gobierno de Duhalde produjo la devaluación de la moneda y la pesificación de los depósitos en dólares en enero de 2002. Como muestran varios estudios esto produjo una transferencia de recursos y nuevas condiciones para los ganadores de la salida de la Convertibilidad (Castellani y Schorr, 2004). Durante el primer trimestre de 2002 continuó la tendencia de caída del nivel de actividad, sin embargo la llegada de Roberto Lavagna al Ministerio de Economía significó una nueva fase en la reestructuración económica y salida gradual de la situación anterior.

\section{Gráfico 1. Evolución del PBI, el desempleo y la informalidad durante el período neoliberal desde 1995}

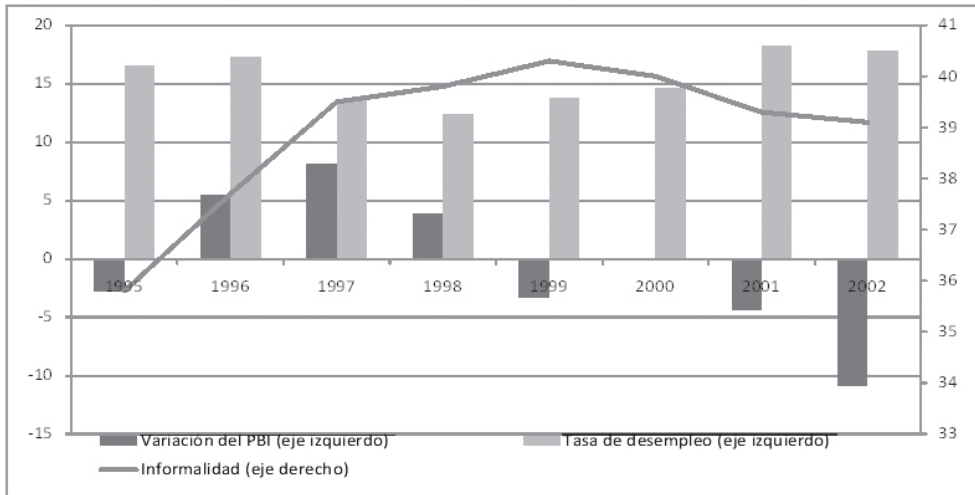

Fuente: Elaboración propia con base en la información del INDEC, Encuesta Permanente de Hogares. Trimestres iv. Variación del PBI hasta 2012 con base en el proyecto ARKLEMS+LAND http://arklems.org/.

Variación del PBI años 2013 y 2014 con base en CEPAL http://interwp.cepal.org/cepalstat

La tasa de formalidad corresponde al percentaje de asalariados registrados repecto del total del empleo asalariado.

Los asalariados que declaran tener descuento jubilatorio se asumen como registrados en la seguridad social.

La salida de la convertibilidad puede considerarse el cierre de la "larga década de los noventa" cuyos indicadores sociales evidencian la situación en la que se encontraba la población.Hacia finales del período neoliberal la desocupación se ubicó en torno a al 18 por ciento de la población, la informalidad cercana al 40 por ciento y el índice de Gini registró su peor medición histórica $(0,54)$. La pobreza, por su parte, según algunos estudios alcanzó al 50 por ciento de la población hacia finales del 2001 y comienzos del 2002. 


\section{Hacia el giro a la izquierda}

En el período posterior, la economía mostró una recomposición de las ganancias de los sectores favorecidos por el tipo de cambio y las condiciones externas en el marco de una situación social que mostraba su peor desempeño en cuanto a empleo, pobreza y desigualdad. En un contexto político inestable, la economía comenzó crecer en el tercer trimestre de ese año y se evidenció una estabilización del precio del dólar que influyó positivamente en el control de la inflación. A diferencia de otras experiencias devaluatorias el impacto en la inflación fue breve, atenuada por la situación económica marcada por la recesión y la baja actividad económica que frenó el traslado a precios en un contexto de escasa liquidez por la perdurabilidad de controles y la delicada situación financiera de los bancos (Kulfas, 2016).

El nuevo contexto macroeconómico favoreció a los sectores productores de bienes y servicios con acceso al mercado internacional y con capacidad instalada. Esto tuvo un efecto positivo en la industria nacional a partir de un nuevo proceso de sustitución de importaciones. El alza de los precios internacionales de los commodities generó un incremento de la rentabilidad de las actividades ligadas a las actividades primarias, aprovechamiento de capacidades instaladas y, como resultado, se generó un crecimiento en las exportaciones. Estos sectores lideraron la recuperación de la actividad pero también fueron acompañados por otros sectores como los ligados a la construcción, la industria y el comercio interno. Esta incipiente recuperación marcó, en algunos casos, inicios de procesos de reversión de la tendencia a la desmejora de indicadores sociales y laborales que se registraba en el país desde los años setenta (Azpiazu y Schorr, 2010).

En lo que concierne a las políticas sociales, el gobierno de Duhalde decretó, primero, la emergencia en materia social y económica y luego la emergencia ocupacional. En este contexto se planteó la creación de un programa orientado transferir recursos a los sectores más pobres a partir de un subsidio a los Jefes y Jefas de Hogar desocupados. En abril de 2002 el decreto 565/02 estableció el Derecho Familiar de Inclusión Social a partir del cual todos los jefes/as de hogar desempleados tenían derecho a un ingreso mínimo mediante el Plan Jefes/as de Hogares Desocupados ${ }^{5}$ que sería gestionado por el Ministerio de Trabajo, Empleo y Seguridad Social y se establecía un monto mensual de 150 pesos. El plan dio cobertura a cerca de 2 millones de beneficiarios en el año 2003 (Golbert, 2004) y se convirtió en uno de los programas de mayor alcance llegando a representar casi el 1\% del PBI (Neffa, 2008).

\section{El gobierno de Néstor Kirchner}

Cuando Néstor Kirchner asume, el 25 de mayo de 2003, se encontró con varios desafíos en materia de política económica y social. Entre los principales se pueden destacar: Primero, la necesidad de recomponer un 
sistema financiero dañado y enfrentar una economía con la circulación de cuasi-monedas. Segundo, establecer una estrategia integral de manejo del tipo de cambio acorde al nuevo patrón de crecimiento. Tercero, negociar la deuda caída en default en diciembre de 2001. Cuarto, renegociar con las empresas privatizadas de servicios públicos un cuadro tarifario tras la pesificación. Quinto, enfrentar la cuestión social marcada por la pobreza, los problemas de empleo, la desigualdad y la desprotección social.

La continuidad de la gestión de Roberto Lavagna al frente del ministerio de Economía marcó la senda de las políticas en materia económica. Las nuevas condiciones del tipo de cambio, el congelamiento de las tarifas de los servicios públicos y el bajo componente de costos salariales ${ }^{6}$ generaron condiciones para el incremento de la actividad con altas tasas de ganancias para el sector empresarial (Santarcángelo y Perrone, 2012).

Algunos autores, como Panigo y Chena (2011) identifican al primer trayecto del gobierno de Néstor Kirchner como parte de un "un régimen de tipo de cambio real neo-mercantilista” motorizado por el consumo de bienes durables y en el que se incrementa tanto la competitividad del sector industrial (también la construcción y el sector de transportes) como las ganancias para el sector agro-exportador en un contexto regresivo de la distribución personal y funcional del ingreso que tiende a recuperarse paulatinamente. Según los autores, este patrón heredado por Néstor Kirchner y gestionado por Lavagna -tipo de cambio real alto, salarios reales bajos, rentabilidad extraordinaria para el sector empresarial y crecimiento impulsado por el consumo de bienes durables- comienza ya a principios de 2005, a encontrar una alternativa. En efecto, a inicios de ese año se reconocen los indicios de "un nuevo modelo de desarrollo estructuralista, de crecimiento impulsado por los salarios, el gasto público social y un novedoso diseño de tipos de cambio múltiples (inspirado en las ideas de Marcelo Diamand y articulado en torno a un esquema de retenciones diferenciales, compensaciones selectivas, exportaciones administradas y protección paraarancelaria) y acuerdos de precios” (Panigo y Chena, 2011,p.252).

En el frente externo se estableció un espacio de negociación para la reestructuración de la deuda en default con una quita cercana al 65\% y un esquema de pago de servicios atado al crecimiento de la economía. La efectivización del canje de la deuda en 2005 alcanzó al 76,2\% con una quita final del 65,6\%. Esta reestructuración parcial de la deuda pública tuvo un significativo impacto en la consolidación de la mejora fiscal (Kulfas, 2016; Creus, 2016).

Hacia fines de ese año Roberto Lavagna fue reemplazado por Felisa Miceli al frente de la cartera de economía. La salida de Lavagna y la contienda electoral de las legislativas de octubre de 2005 -en el que se enfrentaron en el principal distrito electoral (la provincia de Buenos Aires) por la senaduría una lista kirchnerista (con Cristina Fernández de Kirchner a la cabeza) contra una duhaldista (encabezada por Hilda "Chiche” Duhalde)- son parte de un mismo proceso político de afirmación del proyecto de la fuerza guberna- 
mental. La victoria del kirchnerismo contra el único adversario político con capital electoral y capacidad de articulación abrió un espacio de consolidación para el Frente para la Victoria que se coronó en la elección presidencial de 2007 en el marco de una “Concertación Plural” que incluyo a gobernadores y exgobernadores de la UCR.

La consolidación de un esquema económico en el marco del alza de los precios internacionales de los commodities ${ }^{7}$ terminó por estabilizar la economía aunque con un incipiente problema de inflación que tendió a agravarse con el correr de los años. En el intento por mantener la inflación en un dígito, el gobierno apeló al congelamiento de las tarifas de servicios públicos y una política de controles y acuerdos de precios así como la regulación de mercados de especial relevancia para la canasta básica. Sin embargo, se registró un ritmo de incremento de precios promedio en torno al 15\% en 2006. Este incremento de la inflación impactaba negativamente en la estrategia de un tipo de cambio competitivo. La intervención del Instituto Nacional de Estadísticas y Censos (INDEC) desató una controversia pública sobre el status de los indicadores y generó una pérdida en la confianza en las estadísticas oficiales tanto en el plano nacional como internacional.

El problema de la pobreza y la desigualdad, uno de los asuntos de la cuestión social persistentes, fueron encarados, en principio, a partir de la confianza en la reactivación del crecimiento económico y la generación de empleo de calidad asociado como mecanismo de recomposición del ingreso. La política gubernamental situó a los convenios colectivos como una institución para regular la relación entre capital y trabajo. En los primeros años del kirchnerismo el salario real afianzó su tendencia al alza.

El Salario Mínimo Vital y Móvil que en julio de 2003 era de 250 pesos pasó a 630 pesos en julio de 2005. En 2003, por medio de sucesivos decretos, el presidente Kirchner modificó el monto del salario mínimo. Desde 2004 el gobierno convocó al Consejo Nacional del Empleo, la Productividad y el Salario Mínimo, Vital y Móvil como una forma de canalizar mediante a las instituciones de diálogo tripartito la regulación de la relación salarial básica contemplada por ley. Estas políticas orientadas a la recomposición salarial vía las paritarias y vía SMVM constituyen uno de los pilares que identifican Panigo y Chena (2011) como inicio de un cambio significativo en el modelo.

En la recomposición de la institución aboral, fue clave que el gobierno nacional promoviera la reunificación de la CGT que venía de una historia reciente de divisiones entre los principales nucleamientos sindicales. Finalizado el mandato de Rodolfo Daer al frente de la central obrera a mediados de 2004, el gobierno apoyó la conformación de un triunvirato de conducción compuesto por Susana Rueda, Luis Lingeri y Hugo Moyano. Al año siguiente será este último el que asuma como representante de una CGT unificada y aliada al gobierno de Néstor Kirchner (Lucca, 2014). 
La literatura especializada ha identificado en este período nuevas condiciones para la acción de los sindicatos dado que la recomposición de la actividad económica y de los índices de empleo impactaron en la tasa de afiliación sindical, el accionar de los gremios y cambió la dinámica de la conflictividad laboral. Esta nueva situación se evidencia en el sustancial incremento de la negociación colectiva y la firma de convenios entre los sindicatos y los empleadores bajo la supervisión del Estado. La reposición de una institución laboral como la negociación tripartita promovió nuevas condiciones para acuerdos salariales que impactaron en instituciones laborales como el mencionado Salario Mínimo, Vital y móvil y estas en conjunto en la dinámica de los ingresos (Marshall y Perelman, 2006; Kostzer, 2006; Groisman, 2013; Beccaria, Maurizio y Vázquez, 2015).

La recuperación económica a partir del 2002 registró en el sector industrial una expansión considerable. Desde la salida de la convertibilidad hasta el 2008, según Apiazu y Schorr (2010), el sector manufacturero creció un $71.6 \%$. En los primeros años de la post-convertibilidad esta expansión se explica por la convergencia de un tipo de cambio alto, el bajo costo salarial en dólares y la existencia de capacidad ociosa en un contexto de demanda internacional. El sector industrial se consolidó en el mercado interno en un contexto de crecimiento de los salarios reales que activaron el consumo.

La propuesta gubernamental fue explícitamente la de mantener políticas activas de empleo y fomentar el empleo registrado en el marco de un modelo que promovía la inclusión social mediante la recuperación del poder adquisitivo de los asalariados pero también de una política fiscal que conjugó expansión del gasto público y superávit fiscal. Uno de los desafíos que debió enfrentar el gobierno fue evitar los problemas de desequilibrios en la balanza de pagos y, en gran medida, recurrió como ya se mencionó a una estrategia de diferenciación cambiaria o tipo de cambio múltiple para crear condiciones de crecimiento y competitividad (Panigo y Chena, 2011).

Sin embargo, las políticas de transferencias de ingresos siguieron presentes para dar respuesta al núcleo duro de la pobreza y los sectores menos calificados y más vulnerables. El plan Jefes y Jefas que había servido para una relativamente rápida transferencia a los sectores más pobres (los hogares desocupados) comenzaba a evidenciar tanto su retraso en cuanto al monto (en relación con el Índice de Precios al Consumidor y en relación al salario mínimo) como sus limitaciones para la reinserción de los beneficiarios al mercado de trabajo (Gasparini, Haimovich y Olivieri, 2009). El debate -incluso en el seno del gobierno- estaba instalado sobre los alcances de las políticas sociales y del mercado laboral para absorber la mano de obra desocupada en puestos de empleo formales como forma de enfrentar la pobreza y mejorar la distribución del ingreso.

Las controversias sobre las políticas activas, las transferencias condicionadas y las medidas de protección social también se plasmaron en qué dependencia gestionaba los programas. Cabe recordar que el Plan Jefes y Jefas de Hogar Desocupado estuvo bajo la órbita del Ministerio de Trabajo 
Empleo y Seguridad Social, mientras que otros programas de alcance laboral como el "Manos a la Obra" orientado a proveer de insumos al trabajo autogestionado y cooperativo, surgen en la órbita del Ministerio de Desarrollo Social. Como afirma Neffa (2008) lentamente fueron generándose consensos en torno a la necesidad de un cambio en la política de protección social con dos objetivos diferentes: Por un lado garantizar un ingreso para sectores vulnerables y, por otro, capacitar la mano de obra en aras de fortalecer sus competencias para incorporarse al mercado de trabajo formal.

En 2006 se puso en marcha una nueva estrategia de política social orientada a instaurar una nueva fase de programas sociales superadores del plan JJHD y su carácter de contingencia ante la crisis. En este sentido el Programa Familias por la Inclusión Social estaba orientado a garantizar el ingreso de hogares con menores de edad y el Seguro de Capacitación y Empleo destinado a los definidos como empleables, éstas serían las herramientas de la política pública ${ }^{8}$.

El Programa Familias por la Inclusión social fue esbozado en octubre de 2004 como el primer intento de escindir la protección social del mundo laboral y redirigirlo al entorno familiar. En efecto, se dirigió para que las beneficiarias del PJJHD definidas como inempleables puedan migrar a la nueva propuesta asistencial gestionada por el Ministerio de Desarrollo Social $^{9}$. (Campos, Faur y Pautassi, 2007). Como puede apreciarse el objetivo central del programa fue la búsqueda de una protección mínima a las familias en situación de vulnerabilidad social a través de una transferencia monetaria cuyo condicionamiento buscó promover el acceso a la salud y la educación de los menores.

Por su parte, el decreto 336/06 creó el "Seguro de Capacitación y Empleo” bajo la órbita del Ministerio de Trabajo, Empleo y Seguridad Social orientado a que los beneficiarios del Plan Jefes y Jefas de Hogar Desocupado pudieran optar por migrar al nuevo plan. Este ofrecía: un ingreso no remunerativo por período máximo de veinticuatro meses (225 pesos durante los primeros dieciocho meses y 200 pesos los últimos 6) y apoyo para la reinserción laboral a partir de la asistencia para la búsqueda de empleo, la capacitación laboral y la asistencia para las experiencias de autoempleo a través de las Oficinas de Empleo municipales y de la Red de Servicios de Empleo.

La creación de un programa con el objetivo de garantizar un ingreso mínimo en los hogares estructuralmente pobres bajo la órbita del Ministerio de Desarrollo Social y un programa orientado a capacitar a los trabajadores y promover su inserción en el marcado laboral, gestionado por el Ministerio de Trabajo Empleo y Seguridad Social como estrategia de salida de los PJJHD, implicó el reconocimiento de las limitaciones del mercado formal como mecanismo de inclusión y las dificultades para bajar los índices de empleo no registrado y su incidencia en la pobreza (Beccaria y Grosiman, 2008). Si bien la intención fue que progresivamente los beneficiarios de los PJJHD se fueran sumando a uno u otro programa, en la práctica los PJJHD 
siguieron representado un número relevante de los hogares. Según Neffa (2008) para septiembre de 2007, seguían cobrando el plan unos 820 mil beneficiario mientras que migraron al plan Familias 271 mil y al SCE unos 70 mil $^{10}$ y se incorporaron al mercado de trabajo formal $510 \mathrm{mil}$.

El período de gobierno de Néstor Kirchner muestra un auspicioso desempeño en el plano macroeconómico (fuerte crecimiento del PBI) crecimiento de la inversión y una inflación que, aunque comenzaba a evidenciarse problemática, se mantuvo manejable. El superávit fiscal se mantuvo, al igual que el externo en un contexto de crecimiento de los salarios reales y los niveles de ocupación, a la par de la formalización laboral.

\section{Tabla 1: Evolución de algunas variables macroeconómicas y de mercado de trabajo (2003- 2007)}

\begin{tabular}{|c|c|c|c|c|c|c|}
\hline \multirow{2}{*}{ Año } & Variación PIB & $\begin{array}{l}\text { Salario mínimo } \\
\text { real }\end{array}$ & $\begin{array}{l}\text { Salario real } \\
\text { medio }\end{array}$ & \multirow[t]{2}{*}{ Desempleo } & Formalidad & $\begin{array}{l}\text { Gini } \\
\text { Ipcf }\end{array}$ \\
\hline & $\begin{array}{c}\text { (en porcentaje) } \\
a\end{array}$ & $(e n p$ & & & (c) & (d) \\
\hline 2003 & 8,83 & 1491 & 3361 & 14,45 & 56,80 & 0,54 \\
\hline 2004 & 9,02 & 2216 & 3434 & 12,02 & 55,99 & 0,49 \\
\hline 2005 & 9,17 & 2830 & 3820 & 10,04 & 57,89 & 0,48 \\
\hline 2006 & 8,46 & 3241 & 4243 & 8,62 & 59,70 & 0,48 \\
\hline 2007 & 8,23 & 3335 & 4528 & 7,52 & 62,21 & 0,46 \\
\hline \multicolumn{7}{|c|}{$\begin{array}{l}\text { Fuente: Elaboración propia con base en la información del INDEC, Encuesta Permanente de Hogares y Ministerio de } \\
\text { Trabajo Empleo y Seguridad Social } \\
\text { a. Tasa de cambio anual con base en el proyecto ARKLEMS+LAND http://arklems.org/ } \\
\text { b. Trimestre iv. Deflactado por el IPC de } 9 \text { provincias } \\
\text { c. La tasa de formalidad corresponde al porcentaje de asalariados registrados respecto del total del empleo } \\
\text { asalariado. } \\
\text { Los asalariados que declaran tener descuento jubilatorio se asumen como registrados en la seguridad social. Trimestre } \\
\text { iv. } \\
\text { d. Gini del Ipcf = Gini del ingreso per cápita familiar }\end{array}$} \\
\hline
\end{tabular}

\section{El primer gobierno de Cristina Fernández de Kirchner}

Cristina Fernández de Kirchner asumió su primer mandato el 10 de diciembre de 2007 luego de obtener el 45.29\% de los votos contra el 23.04\% de Elisa Carrió. La continuidad con la gestión anterior, del mismo signo y orientación política, se presentaba como un hecho y luego de la estabilización de factores macroeconómicos y sociopolíticos el contexto marcaba condiciones favorables para el planteo de un modelo de desarrollo sustentable que requería políticas correctoras en campos como el inflacionario y el déficit energético. No obstante en los albores de la gestión de CFK dos procesos cambiaron la fisonomía del escenario político y económico: el conflicto con las patronales agropecuarias iniciado en marzo de 2008 y la crisis internacional de ese mismo, la más importante de las últimas décadas a nivel mundial. El intento de subir el monto de los derechos de exportación y establecer un sistema de retenciones móviles por el ministro Martín 
Lousteau buscaba equilibrar cuentas fiscales y se enfocaba en la renta del sector que mayores beneficios había obtenido desde el 2002, tanto por el nivel de precios internacionales como por su reconversión tecnológica (Aronskid, 2010).

Las protestas contra las retenciones estuvieron encabezadas por las entidades empresariales ligadas al agro, la Sociedad Rural Argentina, Confederaciones Rurales Argentinas, la Federación Agraria Argentina, CONINAGRO que formaron una "Mesa de Enlace” para coordinar diferentes protestas que incluyeron actos públicos, suspensión de la comercializacióny cortes de rutas. Lo que inició como un reclamo sectorial se fue expandiendo hasta dominar la escena política e involucrar en la controversia a la oposición política y medios de comunicación que tomaron partido por “el campo”. Luego de casi cuatro meses, la presidenta Cristina Fernández de Kirchner planteó una salida institucional al conflicto enviando al Congreso Nacional una iniciativa para ser tratada por los legisladores la normativa en materia de derechos de exportación. La Ley fue tratada en el senado y se produjo un empate en el que el presidente del Senado (y vicepresidente de la Nación) votó en contra del proyecto del Ejecutivo y la iniciativa quedó sin efecto. Este conflicto afectó profundamente al incipiente gobierno tanto por el cambio en la conflictividad social, como por los actores que la protagonizaron y el resultado institucional de la contienda.

La crisis financiera internacional de 2008 puso en jaque el esquema en el que los países emergentes habían logrado un crecimiento a altas tasas. Hacia fines ese año se produjo una fuerte caída de los precios internacionales de productos claves para la economía argentina. Esta baja en el precio de las commodities afectó el ingreso de divisas y tuvo un costo fiscal significativo. No obstante, las consecuencias de esta situación de inestabilidad internacional fueron morigeradas por el hecho de contar con suficientes reservas y una buena situación de superávit que garantizaba el pago de sus obligaciones financieras (Kulfas, 2016).

Para el año 2009 varios de los países sudamericanos comenzaron a recuperar el ritmo de crecimiento. Sin embargo, ese año Argentina presenta una caída en el PBI y una reducción del superávit fiscal que se conjugó con la dificultad de acceder a financiamiento en los mercados internacionales, debido a su situación con la deuda caída en default en 2001 que no había sido renegociada. La caída en los precios del petróleo cercenaron la posibilidad de contar con el auxilio de aliados (como en el caso de Venezuela) y la situación política restringía la opción de recurrir a organismos internacionales como el FMI. Cabe mencionar, además, que una de las consecuencias de la crisis internacional fue la fuga hacia la calidad por parte de capitales privados que afectaron a las economías como la Argentina.

En diciembre de 2009 la presidenta anunció la creación del Fondo del Bicentenario para el Desendeudamiento y la Estabilidad por el DNU 2010/09 que contemplaba un monto de USD 6.500 millones provenientes de las reservas del Banco Central (BCRA) para destinarlos al pago de los servi- 
cios de la deuda externa. Esta medida generó un conflicto con el presidente del BCRA, Martín Redrado, y una controversia sobre la disposición del uso de reservas por decreto. Finalmente Redrado fue reemplazado por Mercedes Marcó del Pont.

En este período el tipo de cambio sufrió un reacomodamiento en un contexto de caída de depósitos, demanda de divisas e incremento en las tasas de interés. En este contexto se implementaron un conjunto de medidas contracíclicas como el incremento del crédito al sector privado y la implementación del programa de Recuperación Productiva (REPRO) ${ }^{11}$ con el objetivo transferir recursos a las empresas para el pago de salarios y así evitar la caída del empleo.

Para mediados del primer gobierno de la presidenta, la dimensión política se vislumbraba complicada. El resultado de la votación por la ley de retenciones en el Senado, adversa al ejecutivo, y los resultados negativos de los comicios del 2009 donde el propio Néstor Kirchner encabezó la lista de diputados en la Provincia de Buenos Aires, secundado por el gobernados Daniel Scioli y el, por entonces jefe de gabinete, Sergio Massa, fueron claves en la apertura de una nueva fase política en el país. Esta derrotas propiciaron lo que algunos autores llamaron "reporonización” (Rocca Rivarola, 2015) o radicalización progresista (Varesi, 2011).

En este marco se lanzaron una serie de variadas iniciativas políticas tendientes a reconstruir el lugar del gobierno y generar nuevas condiciones de gobernabilidad y una inclusión democrática. El desarrollo del conflicto había dejado en evidencia el rol del sistema de medios y el gobierno incluyó en la agenda el reemplazo de las regulaciones legales que regían el campo de medios audiovisuales a partir de la iniciativa popularizada como "Ley de Medios" lo que originó un incremento del conflicto con entidades dominantes en el sector. También se promovieron leyes tendientes a la expansión de derechos civiles como la habilitación del matrimonio entre personas del mismo sexo o la posibilidad de registrar legalmente el género autopercibido. Estas medidas tuvieron un fuerte impacto simbólico además de permitir el acceso a derechos que venía reclamando la comunidad LGTTB (Biglieri, 2013)

Entra las medidas tendientes a reformular patrones de integración social se destaca la disposición del ejecutivo de promover la reforma del sistema previsional a partir de la sanción de una ley (la 26.425) que fue aprobada en noviembre de 2008 (Mesa-Lago, 2009). La nueva normativa dispuso la estatización de las Administradoras privadas de los Fondos de Jubilaciones y Pensiones (AFJP) y su reemplazo por un Sistema Integrado Previsional Argentino, lo que constituyó a juicio de autores como Beccaria y Danani (2013) un proceso de contra-reforma con respecto a las políticas de protección social de la década del $90^{12}$.

El SIPA unifica el régimen público de reparto al eliminar el componente de capitalización individual del sistema previsional y, por lo tanto, elimina 
el lugar que tenían las AFJP. La medida permitió que el Estado, a través del ANSES, recuperara los aportes de los trabajadores y conformara un Fondo de Sustentabilidad del Sistema Público que fue utilizado para financiar políticas públicas y sociales. Además, la toma de las acciones en manos de las entidades privadas, hizo que el ANSES adquiriera participación en varias empresas ocupando lugares en los directorios de las mismas, para auditar y monitorear la actividad correspondiente.

El decreto 1602/2009 firmado por la presidenta Cristina Fernández de Kirchner introdujo una modificación al régimen de asignaciones familiares para incluir a niños/as y adolescentes de grupos familiares desocupados o en la economía informal que registren ingresos menores al salario, mínimo, vital y móvil ${ }^{13}$. La Asignación Universal por Hijo (AUH) consistió, entonces, en una extensión del sistema de protección previsto (y de larga data) en Argentina. La resolución N ${ }^{\circ}$ 393/2009 de la ANSES, el organismo encargado de gestionar la prestación, reglamenta la puesta en práctica de la AUH y precisa alcances y condiciones. Allí se estipula la obligación por parte del familiar responsable de cumplir los requisitos en cuanto a salud (cumplimiento de los controles y el calendario de vacunación) y escolaridad, en el caso de los menores en edad escolar.

La autoridad de aplicación implementó la Libreta Nacional de Seguridad Social, Salud y Educación para cada menor como modo de registrar las actividades relacionadas a la presentación (Roca, 2011).

La extensión de las asignaciones familiares bajo la forma de la Asignación Universal por Hijo (que en 2011 se amplió mediante la Asignación Universal por Embarazo para Protección Social, Decreto 446/2011) marcó un hito insoslayable no sólo en lo que refiere al enfoque de las políticas de protección social (Hintze y Grassi, 2014) sino también en cuanto al impacto en la pobreza y los ingresos de los hogares (Agis, Cañete \&Panigo, 2009; Gasparini y Cruces, 2010; Bustos y Villafañe, 2012).

Los fondos de la ANSES también sirvieron para financiar otras políticas sociales como el programa Conectar Igualdad en 2010 que, mediante el Decreto 459/2010, estableció el suministro de una notebook a estudiantes y docentes de las escuelas públicas de gestión estatal (y también a entidades de educación especial y de Institutos de Formación Docente).

En lo que refiere específicamente a la cobertura previsional, en este período se empezó a notar el efecto de la moratoria previsional que buscó permitir el acceso jubilatorio a personas que estuvieran en edad en hacerlo pero no cumplían con algunos de los requisitos. En 2005 el decreto 1454/ 2005, introdujo modificaciones a la Ley 24.476 para permitir el acceso a la jubilación a quienes no cumplían 30 años de aportes. Las sucesivas moratorias y la ley de Movilidad ${ }^{14}$ fortalecieron la presencia de la cobertura previsional, fundamentalmente en su alcance ya que para 2009 ésta alcanzaba el 90\% (Curcio y Beccaria, 2011). 
En tanto la AUH se orientó a garantizar un piso mínimo de cobertura de ingreso para los hogares con menores de edad, el Plan "Ingreso Social con Trabajo - Argentina Trabaja” buscó reordenar un espacio del mercado de trabajo que permanecía fuera de los alcances de la economía formal. Este programa fue gestionado por el Ministerio de Desarrollo Social, lanzado mediante la Resolución 3182 del año 2009 y promovió la inscripción y formación de cooperativas de trabajo a partir de convenios con organizaciones de la sociedad civil e instancias subnacionales. El Plan preveía la formación de cooperativas para la realización de capacitaciones laborales y tareas ligadas a la infraestructura local y atención a actividades de mejora habitacional, comunitaria y limpieza. Según los datos del Ministerio de Desarrollo Social, para 2013 el programa alcanzaba a más de 5 mil cooperativas con un total de 189.319 mil trabajadores ${ }^{15}$ (Arcidiácono, Kalpschtrej y Bermúdez, 2014).

Las políticas contra-cíclicas de la segunda parte del primer gobierno de Cristina Fernández de Kirchner se articularon virtuosamente con los síntomas de desaceleración y reversión parcial de la crisis internacional evidenciada en 2009. Sin embargo, las mejoras en el panorama macroeconómico debieron enfrentar el recurrente problema de la inflación que retomaba una senda alcista luego de una merma debido a la situación recesiva generada por la crisis de 2008-2009. El crecimiento económico de $2010(9,2)$ y de $2011(6,5 \%)^{16}$ se conjugó con una recuperación de los salarios reales y una modesta creación de nuevos empleos en el sector privado.

Estos aspectos económicos -mejora del desempeño económico general y las políticas de transferencias de ingresos a los más vulnerablesinterrelacionados con otros estrictamente políticos -una oposición fragmentada y diluida- ayudan a comprender el notable éxito electoral de la fórmula Cristina Fernández de Kirchner y Amado Boudou en octubre de 2011 cuando obtuvieron más del 54 \% de los votos en la primera vuelta.

\section{El segundo gobierno de Cristina Fernández de Kirchner}

El escenario del tercer gobierno kirchnerista evidenció pronto algunos problemas estructurales que condicionarían el período. La dinámica del crecimiento económico y las políticas sectoriales tuvieron un significativo impacto en las importaciones y afectaron el superávit externo (Gerchunoff y Kacef, 2010). El problema de acceso a divisas presionó la demanda de dólares tanto de sectores financieros especulativos como de sectores medios y medio altos que se resguardaban en el dólar o los insumían en consumos o gastos en el exterior (Kulfas, 2016). Además la inflación se instaló como un problema que afectó, especialmente, a los trabajadores de menores ingresos al disminuir el poder adquisitivo de los salarios.

La situación fiscal tendió a agravarse con las condiciones antes descritas, el aumento del gasto público superó los ingresos del fisco llevando el déficit fiscal a un escenario complicado. La política de subsidios al 
consumo de la electricidad, el gas y el agua insumía cada vez más recursos del fisco. La caída del tipo de cambio real producto de la administración del dólar se conjugó con el incremento de las importaciones, entre ellas, las derivadas de consumos energéticos necesarios para sostener la producción y el consumo interno. La fuga de capitales ${ }^{17}$ como la intensificación de la compra de dólares para ahorro generó también una situación de escasez de divisas y políticas orientadas a restringir y regular el mercado de cambio en un contexto de caída de reservas (Gaggero, Gaggero y Rúa, 2015). Las medidas contra la escasez de divisas generaron descontento en sectores medios que participaron de acciones colectivas ("Cacerolazos”) contra las medias del gobierno (Gómez, 2014).

En el marco de un déficit fiscal en el que un importante componente era la mencionada importación de recursos energéticos, en 2012, el gobierno nacional decidió estatizar la mayoría del paquete accionario de la empresa Yacimiento Petrolíferos Fiscales en manos de la española Repsol. El descubrimiento de un yacimiento de combustibles no convencionales (Vaca Muerta) abrió la posibilidad de una nueva etapa en cuestión energética que, no obstante, se vio afectada por el precio internacional del petróleo con su marcada tendencia a la baja hacia finales del año 2014.

El primer año del segundo gobierno de Cristina Fernández de Kirchner debió enfrentar la traducción a demandas políticas de situaciones macroeconómicas como el retraso cambiario, la inflación y la falta de divisas. El déficit industrial y energético en un contexto de cierre de los mercados financieros se hizo cada vez más profundo y las medidas de regulación del mercado fueron objeto de rechazo en movilizaciones sociales en forma de “cacerolazos" que convocaron, fundamentalmente, a sectores medios urbanos. Además, la inflación por un lado y el impuesto a las ganancias por otro, generaban tensiones sociales entre los asalariados (y sus organizaciones) que, en muchos casos, habían apoyado al gobierno nacional (como en el caso de la CGT liderada por Hugo Moyano). Las elecciones de 2013 arrojaron un resultado adverso al oficialismo y un crecimiento de sectores políticos opositores, entre ellos el conducido por Sergio Massa (ex Jefe de Gabinete del primer gobierno de Cristina Fernández de Kirchner) que venció en el principal distrito electoral del país.

A principios de 2014, en un contexto macroeconómico e internacional adverso, se agravó la corrida cambiaria y el Gobierno nacional respondió con una fuerte devaluación (que alentó la liquidación de divisas por parte del sector exportador) y un intento de retornar a los mercados financieros internacionales a partir de cerrarlos acuerdos con Repsol (por la estatización de YPF) y la cancelación de la deuda con el "Club de París”. Sin embargo la sentencia de la Corte Suprema de Justicia de los Estados Unidos que confirmó el fallo del juez neoyorkino Thomas Griesa complicó el panorama financiero internacional para la Argentina. El fallo de Griesa intimaba a la Argentina a pagar el total de la deuda comprada por fondos especulativos que no habían entrado en el canje. Esta situación, en el marco de la cláusula RigthsUponFutureOffers(RUFO) que garantizaba que los tenedo- 
res de bonos canjeados podían acogerse a mejores opciones si estas existían en el futuro, provocó un default por el bloqueo de la justicia norteamericana al pago de las obligaciones del país a otros acreedores. El gobierno introdujo cambios en la conducción del BCRA para implementar un plan de estabilización ante las presiones devaluatorias y la escasez de divisas. La estrategia incluyó un acuerdo con China para fortalecer las reservas y estímulos al sector agroexportador para la liquidación de las divisas producto de la cosecha. Según Kulfas (2016) la perspectiva de un cambio de gobierno con mejores relaciones con los mercados también ayudó a que actores económicos importantes busquen posicionarse en el mercado local a la espera de un nuevo clima de negocios.

En lo que respecta a los programas sociales y de protección social, el segundo gobierno de Cristina Fernández de Kirchner se caracterizó por el sostenimiento de los pilares establecidos en los períodos anteriores. El sostenimiento del poder adquisitivo de la AUH en un contexto de crecimiento de la inflación fue una disposición que se articuló con la movilidad jubilatoria dispuesta por ley. Los fondos del ANSES se enfocaron en dos programas que tuvieron relativo éxito (aunque un alcance limitado) como el Programa de Respaldo a Estudiantes Argentinos (Prog.r.es.ar) y el Pro.Cre.Ar (Programa Crédito Argentino del Bicentenario para la Vivienda Única Familiar). El Pro.Gre.s.ar, creado en 2014, consiste en una prestación de \$900 mensuales destinada a los estudiantes desempleados o en condiciones de informalidad cuyos hogares no reciben ingresos superiores a tres salarios mínimos, vitales y móviles. Para acceder a ella, el joven debe acreditar la asistencia a una institución educativa de gestión estatal o autorizada por el Ministerio de Educación, o a centros de formación acreditados ante el Ministerio de Trabajo, Empleo y Seguridad Social. Algunos estudios (Giovambattista, Gallo, y Panigo, 2014) han mostrado su incidencia positiva en la distribución del ingreso así como en la capacitación de sectores vulnerables. Mientras que otros trabajos (Colina y Giordano, 2014) han puesto reparos en cuanto al alcance del programa. El Pro.Cre.Ar, por su parte, fue creado por el decreto presidencial 902 del 2012 a través de un fondo fiduciario público con el objetivo de promover el crédito para la construcción de viviendas y desarrollo de proyectos urbanísticos e inmobiliarios particularmente orientado a la vivienda familiar única. Esta política contendía el propósito de incidir positivamente en el acceso al crédito inmobiliario -tradicionalmente bajo en Argentina (Rodulfo, \&Boselli, 2015)- promover soluciones habitacionales y reactivar sectores de la economía dinámicos ligados a la construcción.

En el escenario político, luego de la derrota electoral del 2013, se produjo cierta incertidumbre en la fuerza gubernamental en cuanto a la estrategia electoral a desplegar para enfrentar a los dos candidatos que contaban con el respaldo de los grandes medios de comunicación: Mauricio Macri y Sergio Massa. En un contexto de bajo crecimiento, tensiones macroeconómicas en un escenario inflacionario, con creciente déficit fiscal y un frente externo complicado por la amenaza de los fondos buitres y las expectativas de actores trasnacionales sobre una posible alternancia, el 
Frente para la Victoria definió la fórmula Daniel Scioli - Carlos Zannini para competir en la elecciones presidenciales. Este binomio fue derrotado por la fórmula integrada por Mauricio Macri y Gabriel Michetti en la segunda vuelta realizada en noviembre de 2015.

La última fase del gobierno de Cristina Fernández de Kirchner evidenció un amesetamiento del crecimiento y de la mejora en los indicadores sociales y del mercado de trabajo, al tiempo que una continuidad con ciertos problemas estructurales como la consolidación del déficit fiscal, la inflación y la restricción del acceso a divisas (sujetas en parte a la especulación de los sectores agro-exportadores). Algunos autores -como Gerchunoff y Kacef, 2016) definen este período como la búsqueda de un "objetivo residual” constituido por generar una administración política y económica que evite una crisis en momentos previos a la disputa electoral que definiría la sucesión presidencial.

\section{Tabla 2: Evolución de algunas variables macroeconómicas y de mercado de trabajo, 2008-2014}

\begin{tabular}{|c|c|c|c|c|c|c|}
\hline \multirow[t]{2}{*}{ Año } & Variación PIB & Salario mínimo real & Salario real medio & \multirow[t]{2}{*}{ Desempleo } & \multirow{2}{*}{$\begin{array}{c}\text { Formalidad } \\
\text { (c) }\end{array}$} & \multirow{2}{*}{$\begin{array}{l}\text { Gini } \\
\text { Ipcf } \\
\text { (d) }\end{array}$} \\
\hline & (en porcentaje) a & \multicolumn{2}{|c|}{ (en pesos) $b$} & & & \\
\hline 2008 & 4,38 & 3301 & 4481 & 7,28 & 63,53 & 0,45 \\
\hline 2009 & $-3,43$ & 3400 & 4643 & 8,37 & 64,78 & 0,45 \\
\hline 2010 & 9,25 & 3337 & 4873 & 7,30 & 67,05 & 0,44 \\
\hline 2011 & 6,52 & 3574 & 5159 & 6,74 & 66,74 & 0,44 \\
\hline 2012 & $-0,52$ & 3359 & 5004 & 6,90 & 66,24 & 0,41 \\
\hline 2013 & 2,3 & 3300 & 5185 & 6,40 & 67,29 & 0,41 \\
\hline 2014 & $-2,6$ & 3216 & 5013 & 6,90 & 66,73 & 0,42 \\
\hline \multicolumn{7}{|c|}{$\begin{array}{l}\text { Fuente: Elaboración propia con base en la información del INDEC, Encuesta Permanente de Hogares y Ministerio de } \\
\text { TrabajoEmpleo y Seguridad Social } \\
\text { a. Tasa de cambio anual con base en el proyecto ARKLEMS+LAND http://arklems.org/. Años } 2013 \text { y } 2014 \text { con base en } \\
\text { CEPAL http://interwp.cepal.org/cepalstat } \\
\text { b. Trimestre iv. Deflactado por el IPC de } 9 \text { provincias } \\
\text { c. La tasa de formalidad corresponde al porcentaje de asalariados registrados respecto del total del empleo } \\
\text { asalariado. } \\
\text { Los asalariados que declaran tener descuento jubilatorio se asumen como registrados en la seguridad social. Trimestre iv. } \\
\text { d. Gini del Ipef = Gini del ingreso per cápita familiar }\end{array}$} \\
\hline
\end{tabular}

\section{Conclusiones}

A lo largo del artículo se ha evidenciado el proceso en etapas, de las tensiones, posibilidades y alcances de la dinámica distributiva derivada de las políticas y el contexto político y económico.La menor desigualdad del ingreso fue posible en un contexto de potencialidades y restricciones externas, así como también en función de la dinámica interna que ha caracterizado a los gobiernos progresistas. Los indicadores dan muestra de una mejora en la situación social.No obstante este incremento en la democracia socio-económica y la ampliación de derechos (vía implementación de políticas públicas concretas) el proceso tuvo problemas, especialmente, en los momentos en que no pudo cumplir promesas (ligadas al bienestar y la inclusión) debido a restricciones externas y/o internas del propio modelo de 
acumulación, así como a las limitaciones que otros actores imponen al accionar político.

Asimismo las tareas pendientes o incompletas marcaron restricciones en la conformación de escenarios para dar la disputa política. La ruptura de alianzas con actores sociales que habían conformado el bloque gubernamental (como los sindicatos enrolados en la CGT), así como la pérdida de consensos en amplios sectores de la población ${ }^{18}$ y ciertas particularidades de las formas de representación (y participación) de la ciudadanía, instalaron condiciones para la derrota electoral de Daniel Scioli, el candidato queen las elecciones presidenciales de 2015 planteaba, para algunos, la continuidad de los objetivos de inclusión social democrática trazados por el Kirchnerismo.

Gráfico 2. Indicadores sociales 1995-2014

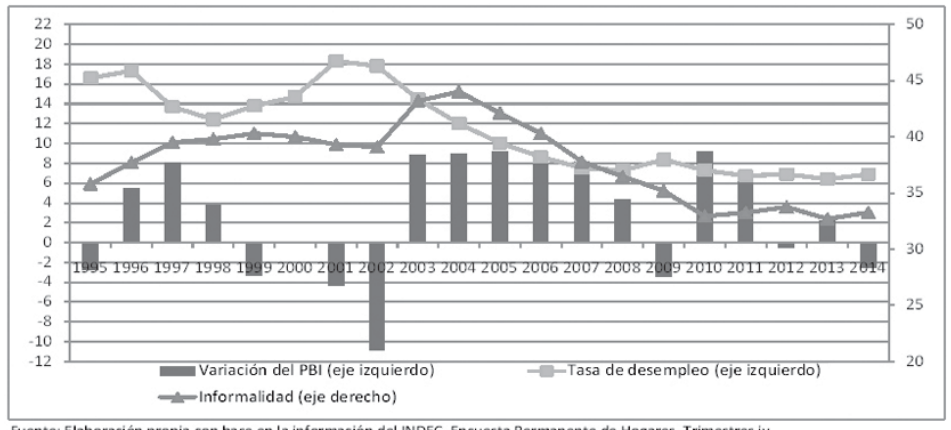

Fuente: Elaboración propia con base en la información del INDEC, Encuesta Permanente de Hogares. Trimestres iv.

Variación del PBI hasta 2012 con base en el proyecto ARKLEMS+LAND http://arklems.org/.

Variación del PBI años 2013 y 2014 con base en CEPAL http://interwp.cepal.org/cepalstat

La tasa de formalidad corresponde al percentaje de asalariados registrados repecto del total del empleo asalariado.

Desde su asunción, el gobierno de Mauricio Macri, direcciona un reordenamiento del patrón de distribución del ingreso. Las medidas de liberalización del tipo de cambio y de las importaciones, así como la exoneración del pago de impuestos a sectores de la economía vinculados con los agronegocios (soja) o la explotación de recursos naturales (megaminería) y la concesión de aumento de tarifas de los servicios públicos han generado transferencias de recursos hacia los sectores altos. El contexto de una economía que no da señales de un dinamismo positivo, junto con la imposibilidad de bajar la alta inflación, hace que los trabajadores de los sectores medios y populares reciban un impacto negativo en el nivel y poder adquisitivo de sus ingresos.

El giro a la derecha en la orientación del gobierno pone en perspectivas los alcances y las limitaciones de los gobiernos anteriores y plantea desafíos para los actores organizados y los investigadores motivados por comprender el proceso y aportar en una perspectiva de reposicionamiento de la democracia económica, social y ciudadana. 
Polis, Revista Latinoamericana, Volumen 16, $N^{\circ}$ 46, 2017

\section{Notas}

${ }^{1}$ Para una revisión del debate puede consultarse Stoessel (2014) en esta misma revista.

2 Según Betranou y Paz (2007) el Plan Trabajar I tuvo una "relativamente” buena focalización al alcanzar a las familias pobres.

${ }^{3}$ La medición del INDEC de octubre de 2001 arrojó que un 35\% de las personas vivían bajo la línea de pobreza y la tasa de desocupación ascendía al 19\%.

${ }^{4}$ El gobierno de la Alianza se propuso implementar un programa inspirado en el PROGRESA mexicano denominado "Solidaridad” pero, según Goldbert (2004) nunca se logró materializar.

${ }^{5}$ El decreto establece “Art. $2^{\circ}$ - Créase el PROGRAMA JEFES DE HOGAR para ser aplicado mientras dure la EMERGENCIA OCUPACIONAL NACIONAL(1), que por este decreto se ratifica hasta el 31 de diciembre de 2002, destinado a jefes/as de hogar con hijos de hasta DIECIOCHO (18) años de edad, o discapacitados de cualquier edad, y a hogares en los que la jefa de hogar o la cónyuge, concubina o cohabitante del jefe de hogar se hallare en estado de gravidez, todos ellos desocupados y que residan en forma permanente en el país”.

${ }^{6}$ Según Damill y Frankel (2010) “el salario medio en la industria manufacturera había declinado, a fines de 2003, medido en dólares, a un valor equivalente a alrededor de $40 \%$ del vigente antes de la crisis” (p.3)

${ }^{7}$ MaristellaSvampa(2013) refiere a este proceso como "consenso de los commodities".

${ }^{8}$ Esta definición originó debates y críticas de los especialistas en políticas sociales, véase:Campos, et al. (2007)

${ }^{9}$ El decreto 1506/2004 estipula centralmente:

“Art. $3^{\circ}$ - Fíjase un plazo de ciento ochenta (180) días contados a partir del $1^{\circ}$ de enero de 2005 para que los Ministerios de trabajo, empleo y seguridad social y de Desarrollo social en forma conjunta y sobre la base de los datos con que a la fecha cuentan ambas jurisdicciones, realicen una clasificación de los beneficiarios del programa jefes de hogar de acuerdo a las condiciones de empleabilidad que, eventualmente, reúnan los mismos. A tal fin definirán los requisitos y perfiles que deban acreditar los interesados. Dicho plazo podrá ser prorrogado por igual término y por única vez por resolución conjunta de los citados Ministerios.

Art. $4^{\circ}$ - Los beneficiarios con posibilidades de empleo continuarán percibiendo sus beneficios en la órbita del Ministerio de trabajo, empleo y seguridad social, que entenderá en todo lo atinente a la inserción y reinserción laboral de los destinatarios, a través de programas específicos y/ o acciones de empleo transitorio, formación profesional y promoción del empleo privado.

Art. $5^{\circ}$ - Los beneficiarios del programa jefes de hogar que no fueran calificados de acuerdo a lo dispuesto en el artículo $4^{\circ}$ del presente, podrán ser incorporados a los programas destinados a la atención de grupos vulnerables, la mejora de ingresos y de desarrollo humano creados o a crearse en el Ministerio de desarrollo social. 
10 Según Betranou y Paz (2007) para el último tramo del mandato de Néstor Kirchner el seguro por desempleo cubría a 92 mil personas mensualmente con un ingreso promedio de 430 pesos que equivalía al 54\% del salario mínimo, vital y móvil.

${ }^{11}$ El programa, creado mediante la resolución 481/2002 del MTEySS y relanzado en 2008 estipula el pago de una suma fija mensual remunerativa hasta el monto equivalente al salario mínimo, vital y móvil hasta por 12 meses y hasta completar el monto salarial de la categoría laboral correspondiente. Según los datos el MTEySS (2010:70) el programa alcanzó en 2009 a más de 143 mil trabajadores de 2769 establecimientos (el $77 \%$ de menos de 50 empleados)

${ }^{12}$ Esta medida tuvo un antecedente cuando mediante la sanción de la Ley $\mathrm{N}^{\circ} 26.222$ a principios de 2007 se habilitó la posibilidad de opción (una vez cada cinco años) entre el Régimen Previsional Público de Reparto o el Régimen de Capitalización Individual.

${ }^{13}$ Artículo $1^{\circ}$ Incorpórese como inciso c) del artículo $1^{\circ}$ de la Ley $N^{\circ} 24.714$ y sus modificatorios, el siguiente texto:

“c) Un subsistema no contributivo de Asignación Universal por Hijo para Protección Social, destinado a aquellos niños, niñas y adolescentes residentes en la República Argentina, que no tengan otra asignación familiar prevista por la presente ley y pertenezcan a grupos familiares que se encuentren desocupados o se desempeñen en la economía informal."

Art. $2^{\circ}$ - Incorpórase al artículo $3^{\circ}$ de la Ley $\mathrm{N}^{\circ} 24.714$ y sus modificatorios el siguiente párrafo:

"Quedan excluidos del beneficio previsto en el artículo $1^{\circ}$ inciso c) de la presente los trabajadores que se desempeñen en la economía informal, percibiendo una remuneración superior al salario mínimo, vital y móvil.”

${ }^{14}$ La Ley $N^{\circ} 26.417$ de 2008 estableció un mecanismo bianual de actualización de haberes a partir de un índice que incluye la evolución salarial (tasa de reemplazo) y los recursos de la ANSES, cuya concreción se estipuló para los meses de marzo y septiembre. Con esta Ley, la movilidad de las prestaciones previsionales es computada a partir de un índice que contempla dos aspectos: por un lado, considera la evolución de los salarios, base de la actualización de la tasa de reemplazo y, por otra parte, considera la evolución de los recursos de la ANSES, base de la sostenibilidad financiera del sistema previsional.

${ }^{15}$ Fuente http://www.desarrollosocial.gob.ar/informes/argentina-trabaja-un-camino-deinclusion-social/ (visitado, 14 de noviembre de 2016) También: Roca, E., Golbert, L., y Lanari, M. E. (2012). ¿Piso o sistema integrado de protección social? Una mirada desde la experiencia argentina.

16 Datos de crecimiento: Tasa de cambio anual con base en el proyecto ARKLEMS+LAND http://arklems.org/

${ }^{17}$ Según Martín Schorr y Andrés Wainer (2015) un primer hito en la fuga se dio luego del conflicto "Campo-gobierno" y en el marco de la crisis internacional de 2008. Luego se sucedieron episodios en 2010 y 2012.

${ }^{18}$ El estudio del proceso de pérdida de consenso del gobierno nacional y el rol de los medios es un aspecto clave que excede este trabajo. 


\section{Referencias}

Agis, E., Cañete, C. yPanigo, D. (2010). El impacto de la Asignación Universal por Hijo en Argentina. Recuperadohttp://www.trabajo.gov.ar/ left/estadisticas/DocumentosSUBWEB/area1/documentos/ AUH_en_Argentina.pdf

Altimir, O., yBeccaria, L. (2001). El persistente deterioro de la distribución del ingreso en la Argentina. Desarrollo económico, 40(160),589618.DOI: $10.2307 / 3455997$

Arcidiácono, P., Kalpschtrej, K. y Bermúdez, A. (2014). ¿Transferencias de ingresos, cooperativismo o trabajo asalariado?: El Programa Argentina Trabaja. Trabajo y sociedad: Indagaciones sobre el empleo, la cultura y las prácticas políticas en sociedades segmentadas, (22). Recuperado de http://www.scielo.org.ar/pdf/tys/n22/n22a19.pdf

Aronskind, R. (2010). Cambio estructural y conflicto distributivo: el caso del agro argentino. En Aronskind, R.yVommaro, G. Campos de batalla. Las rutas, los medios y las plazas en el nuevo conflicto agrario.(pp. 327-353). Buenos Aires, Argentina: UNGS-Prometeo.

Azpiazu, D.\&Schorr, M. (2010). La industria argentina en la posconvertibilidad: reactivación y legados del neoliberalismo. Problemas del desarrollo, 41(161), 111-139. Recuperado de http://www.scielo.org.mx/pdf/prode/v41n161/v41n161a5.pdf.

Bambaci, J., Saront, T. \&Tomassi, M. (2000).La Economía Política de las Reformas Económicas en la Argentina. Cuadernos de economía, 37(112), 495-536. Recuperado de http://www.scielo.cl/ scielo.php?script=sci_arttext\&pid=S071768212000011200004\&lng=en\&nrm= iso\&tlng=en.

Basualdo, E. (2003). Las reformas estructurales y el Plan de Convertibilidad durante la década de los noventa. Revista Realidad Económica (200). Recuperado de http://legacy.flacso.org.ar/uploaded_files/ P u b l i c a c i o n e s/ 27 _ A E Y T_L a s. re f or m a s. estructurales.y.el.Plan.de.Convertibilidad.p̄ff

Basualdo, E. (2006). Estudios de historia económica argentina: desde mediados del siglo XX a la actualidad. Buenos Aires, Argentina: FLACSO.

Beasley-Murray, J., Cameron, M. A. y Hershberg, E. (2009). Latin America’s left turns: anintroduction. Third World Quarterly, 30(2), 319330.DOI:

Beccaria, A. y Danani, C. (2013). La política previsional argentina 20032011: balances, desafíos e incógnitas sobre la protección. Argumentum, 4(2), 59-79. Recuperado de http:// 
w w w. re d a l y c. org/pd f/ $4755 / \mathrm{R}$ e s u m e n e s / Resumen_475547481007_1.pdf

Beccaria, L., Maurizio, R. y Vázquez, G. (2015). Desigualdad e informalidad en América Latina: el caso de la Argentina. En Amarante, V. y Arim, R. (Eds.) Desigualdad e informalidad: un análisis de cinco experiencias Latinoamericana (133) Santiago, Chile: CEPAL. Recuperado de http://www.cepal.org/es/publicaciones/37856-desigualdadinformalidad-un-analisis-cinco-experiencias-latinoamericanas.

Beccaria, L. y Groisman, F. (2008). Informalidad y pobreza en Argentina. Investigación económica, 67(266), 135-169. Recuperado de http://www.scielo.org.mx/pdf/ineco/v67n266/v67n266a5.pdf

Beccaria, L. y López, N. (1996). Notas sobre el comportamiento del mercado de trabajo urbano. En Beccaria y Lopez (comp.) Sin trabajo. Las características del desempleo y sus efectos en la sociedad argentina. (pp. 17-46). Buenos Aires, Argentina: UNICEF/Losada.

Bertranou, F., Rofman, R. y Grushka, C. (2003). From reform to crisis: Argentina's pension system. International Social Security Review, 56(2), 103-114DOI: 10.1111/1468-246X.00160

Bertranou, F. y Bonari, D. (2005). Protección social en Argentina: financiamiento, cobertura y desempeño 1990-2003. Santiago. Chile: Oficina Internacional del Trabajo.

Bertranou, F. y Paz, J. (2007). Políticas y programas de protección al desempleo en Argentina. Buenos Aires, Argentina: Oficina Internacional del Trabajo.

Biglieri, P. (2013). Emancipaciones. Acerca de la aprobación de la ley del matrimonio igualitario en Argentina. Iconos. Revista de Ciencias Sociales, (46), 145-160. DOI: http://dx.doi.org/10.17141/ iconos.46.2013.97

Bustos, J. y Villafañe, S (2011).Asignación Universal por Hijo. Evaluación de impacto en los ingresos de los hogares y el mercado de trabajo. Serie Estudios: Trabajo Ocupación y Empleo (10). Buenos Aires, Argentina: Ministerio de Trabajo Empleo y Seguridad Social.

Campos, L., Faur, E. y Pautassi, L. (2007). Programa Familias por la inclusión social: Entre el discurso de derechos y la práctica asistencial. Colección investigación y análisis (4). Buenos Aires, Argentina: CELS.Recuperado de http://www.cels.org.ar/common/documentos/ programa_familias_web.pdf

Castellani, A. y Schorr, M. (2004). Argentina: convertibilidad, crisis de acumulación y disputas en el interior del bloque de poder 
económico. Cuadernos del CENDES, 21(57), 55-81. Recuperado de http://www.redalyc.org/articulo.oa?id=40305703

Castillo, V., Cesa, V., Filippo, A., Rojo, S., Schleser, D. y Yoguel, G. (2002). Dinámica del empleo y rotación de empresas: la experiencia en el sector industrial de Argentina desde mediados de los años noventa (Vol. 9). Serie Estudios y Perspectivas. Buenos Aires, Argentina: CEPAL. Recuperado de http://www.trabajo.gov.ar/left/ estadisticas/descargas/oede/lcbuel178.pdf

Cetrángolo, O. y Grushka, C. (2004). Sistema previsional argentino: crisis, reforma y crisis de la reforma. Serie Financiamiento del Desarrollo, 151. Santiago, Chile: CEPAL. Recuperado de http:// repositorio.cepal.org/bitstream/handle/11362/5133/ S0411870_es.pdf?sequence=1\&isAllowed $=y$

Creus, N. (2016). Argentina y la autonomía en la globalización financiera. La naturaleza de su respaldo durante el proceso de reestructuración de su deuda externa (2002-2005). Papel Político, 20(2).DOI: http:// dx.doi.org/10.11144/Javeriana.papo20-2.augf

Curcio, J. y Beccaria, A. (2011). Sistema de seguridad social y mercado de trabajo: evolución de la cobertura en la Argentina entre 1990 y 2010. En Danani, C. y Hintze, S. (coords.) Protecciones y desprotecciones: la seguridad social en la argentina 1990-2009. (pp. 61-101). Los Polvorines, Argentina: Universidad Nacional de General Sarmiento.

Damill, M. y Frenkel, R. (2013). La economía argentina bajo los Kirchner: una historia de dos lustros. Documentos Técnicos, Iniciativa para la Transparencia Financiera.

Damill, M., Frenkel, R., y Juvenal, L. (2003). Las cuentas públicas y la crisis de la convertibilidad en la Argentina. Desarrollo económico, 43(170), 203-230.DOI: $10.2307 / 3455821$

Damill, M., Frenkel, R. y Maurizio, R. (2003). Políticas macroeconómicas y vulnerabilidad social: La Argentina en los años noventa. Serie Financiamiento del Desarrollo. Santiago, Chile: CEPAL. Recuperado de http://www.itf.org.ar/pdf/documentos/14-2003.pdf

Etchemendy, S. y Collier, R. (2007). Down but Not Out: Union Resurgence and Segmented Neocorporatism in Argentina (2003-2007). Politics and Society, 35(3), 363-401. DOI: 10.1177/0032329207304318

Filipetto, S., Pontoni, G. A. y Trajtemberg, D. (2015).Mercado de trabajo y relaciones laborales en Argentina entre 2003-2013. Avances y temas pendientes. Buenos Aires, Argentina: Congreso Nacional de Estudios del Trabajo. 
Gaggero, A., Gaggero, J. y Rúa, M. (2015). Principales características e impacto macroeconómico de la fuga de capitales en Argentina. Problemas del desarrollo, 46(182), 67-90. DOI: https:// doi.org/10.1016/j.rpd.2015.06.002

Gaggero, J., Rua, M. y Gaggero, A. (2013). Fuga de capitales III. Argentina (2002-2012). Documento de Trabajo(52). Buenos Aires: Centro de Economía y Finanzas para el desarrollo de Argentina. Recuperado de http://www.justiciafiscal.org/wp-content/uploads/2014/06/DT-Nº 52ARGENTINA._FUGA_DE_CAPITALES_III_-web.pdf

Gasparini, L., Haimovich, F., y Olivieri, S. (2009). Labor informality bias of a poverty-alleviation program in Argentina. Journal of Applied Economics, 12(2), 181-205. DOI:https://doi.org/10.1016/S15140326(09)60012-X

Gasparini, L. y Cruces, G. (2010). Las Asignaciones Universales por Hijo: impacto, discusión y alternativas. Documentos de Trabajo $N^{\circ} 102$. CEDLAS. Recuperado de http://163.10.34.134/bitstream/handle/ 10915/3668/Documento_completo__.pdf?sequence=1

Gerchunoff, P. y Kacef, O. (2016) ¿Y ahora qué hacemos? La economía política del Kirchnerismo. Documentos de Trabajo IELAT, $\mathrm{N}^{\circ} 87$. Recuperado de http://ielat.com/inicio/repositorio/Documentos_ de_Trabajo/DT_87_PabloGerchunoff_Web_2.pdf

Gerchunoff, P., y Torre, J. (1996). La política de liberalización económica en la administración de Menem. Desarrollo Económico, 36(143), 733768. DOI: $10.2307 / 3467293$

Giovambattista, A., Gallo, P. y Panigo, D. (2014). El impacto distributivo del “PROG.R.ES.AR” en Argentina. Una primera aproximación en base a microsimulaciones. En Empleo, desempleo y políticas de empleo $\mathrm{N}^{\circ} 17$. CEIL-CONICET.Recuperado de http://www.ceilconicet.gov.ar/wp-content/uploads/2016/04/EDPE17.pdf

Golbert, L. (2004). ¿Derecho a la inclusión o paz social? Plan Jefas y Jefes de Hogar Desocupados. Serie Políticas Sociales $N^{\circ}$ 84. Santiango De Chile:CEPAL. Recuperado de http://repositorio.cepal.org/bitstream/ handle/11362/6071/1/S043172_es.pdf

Gómez, M. (2014). Radiografía de los movilizados contra el kirchnerismo. Resultados de una encuesta a la concurrencia del 8N. Sudamérica: Revista de Ciencias Sociales, (3), 75-100. Recuperado de http:// fh.mdp.edu.ar/revistas/index.php/sudamerica/article/view/1052/1084

González, M (2003): Transformaciones de hecho y de derecho en las relaciones laborales en los 90. En:Lindenboim, J. y Danani, C. (coord.) Entre el trabajo y la política. Las reformas de las políticas sociales 
argentinas en perspectiva comparada(pp. 89-103). Buenos Aires: Biblos.

Groisman, F. (2013). Salario mínimo y empleo en Argentina. Revista de economía política de Buenos Aires, (11), Recuperado de http:// bibliotecadigital.econ.uba.ar/download/ecopoli/ ecopoli_v6_n11_03.pdf

Kessler, G. (2015). Controversias sobre la desigualdad: Argentina, 20032013. Buenos Aires, Argentina: Fondo de Cultura Económica.

Kostzer, D. (2006). Argentina: la recuperación del salario mínimo como herramienta de política de ingresos. En Marinakis, A. y Velasco, J. (eds): ¿Para qué sirve el salario mínimo? Elementos para su determinación en los países del Cono Sur(pp. 35-104). Santiago, Chile: Oficina Internacional del Trabajo.

Kulfas, M. (2016). Los tres Kirchnerismos. Una historia de la economía argentina. 2003-2015. Buenos Aires, Argentina: Siglo Veintiuno Editores.

Lucca, J. (2014). Conflictos y realineamientos de los actores sociales y políticos durante el gobierno de Néstor Kirchner. Sudamérica: Revista de Ciencias Sociales, (3), 27-50. Recuperado de http:// fh.mdp.edu.ar/revistas/index.php/sudamerica/article/view/1049/ 1081

Marshall, A. (2009). Desigualdad interindustrial de salarios, 2003-2008: ¿Reversión a los patrones históricos?Estudios del TrabajoN ${ }^{\circ}$ 37/ 38. Recuperado de http: //www.aset.org.ar/docs/Marsha 11\%2037\%2038.pdf

Maurizio, R. (2014). El impacto distributivo del salario mínimo en la Argentina, el Brasil, Chile y el Uruguay. Serie Políticas Sociales, № 194 (LC/L.3825). Santiago de Chile: Comisión Económica para América Latina y el Caribe (CEPAL). Recuperado de http:// repositorio.cepal.org/bitstream/handle/11362/37208/1/ LCL3825_es.pdf

Mesa-Lago, C. (2009). La ley de reforma de la previsión social argentina. Antecedentes, razones, características y análisis de posibles resultados y riesgos. Nueva sociedad, (219), 14-30.

Neffa, J. (2008). Desempleo, pobreza y políticas sociales. Fortalezas y debilidades del Plan Jefas y Jefes de Hogar Desocupados. Buenos Aires, Argentina: Miño y Dávila.

Novick, M., Lengyel, M. y Sarabia, M. (2009). De la protección laboral a la vulnerabilidad social. Reformas neoliberales en la Argentina. Revista 
Internacional del Trabajo, 128: 257-275. DOI: 10.1111/j.15649148.2009.00060.X

O’donnell, G. (1992). Delegative Democracy?. Working paper \#172. Helen Kellogg Institutefor International Studies. Recuperado de http:// kellogg.nd.edu/publications/workingpapers/WPS/172.pdf

Panigo, D. y Chena, P. (Coords.) (2011). Del neo-mercantilismo al tipo de cambio múltiple para el desarrollo. Los dos modelos de la postConvertibilidad. Ensayos en honor a Marcelo Diamand. Las raíces del nuevo modelo de desarrollo argentino y del pensamiento económico nacional.Buenos Aires: Miño y Dávila/CEIL-PIETTE/Universidad Nacional de Moreno.

Pérez, P.yFéliz, M. (2010). La crisis económica y sus impactos sobre la política de empleo e ingresos en Argentina. RevistaSer Social, 12(26), 31-58. Recuperado de http://www.memoria.fahce.unlp.edu.ar/ art_revistas/pr.4653/pr.4653.pdf

Roca, E. (2011). Asignación Universal por Hijo (AUH): extensión de las asignaciones familiares. Revista Debate Público. Reflexión de Trabajo Social, 1(1). Recuperado de http://www.edumargen.org/docs/curso46-1/unid03/apunte03_03.pdf

Rocca Rivarola, M. (2015). De Néstor y Cristina. De Perón y Evita. Reflexiones sobre lo acontecido con la militancia kirchnerista y la identidad peronista desde 2003 hasta hoy. Revista SAAP, 9(1), 143-17. Recuperado de http://www.scielo.org.ar/scielo.php?script= sci_arttext\&pid=S1853-19702015000100006

Rodulfo, M. y Boselli, T. (2015). Política habitacional en Argentina y desigualdades territoriales. Vivienda y Ciudad, (2), 30-41. Recuperado de https://revistas.unc.edu.ar/index.php/ReViyCi/article/view/13173/13370

Santarcángelo, J. y Perrone, G. (2012). La cúpula empresarial e industrial en Argentina durante la post-Convertibilidad: transformaciones, rentabilidad y empleo. Análisis económico, 64(27) 213-232. Recuperado de http://www.redalyc.org/html/413/41324545010/

Schorr, M., \&Wainer, A. (2015). Algunos determinantes de la restricción externa en la Argentina. Márgenes Revista de Economía Política, 33. Recuperado de http://www.ungs.edu.ar/ms_publicaciones/wpcontent/uploads/2016/08/9772362193003-completo.pdf

Schorr, M. y Ortiz, R (2006). La economía política del gobierno de Alfonsín: creciente subordinación al poder económico durante la “década perdida”. En Pucciarelli, A. (coord.): Los años de Alfonsín. ¿El poder de la democracia o la democracia del poder? Buenos Aires, Argentina: Siglo XXI Editores. 
Stoessel, S. (2014). Giro a la izquierda en la América Latina del siglo XXI: Revisitando los debates académicos. Polis 13(39), 123-149. DOI: http://dx.doi.org/10.4067/S0718-65682014000300007

Svampa, M. (2013). Consenso de los Commodities y lenguajes de valoración en América Latina. Nueva sociedad, (244), 30-46. Recuperado de http://nuso.org/articulo/consenso-de-los-commodities-y-lenguajesde-valoracion-en-america-latina/

Colina, J. y Giordano, O. (2014). Estrategias para enfrentar la discriminación laboral que afecta a los jóvenes. Empleo y desarrollo social: serie informes de la economía real 8(39). Buenos Aires: Universidad Católica Argentina. Facultad de Ciencias Económicas. Escuela de Economía “Francisco Valsecchi”. Recuperado de http:// bibliotecadigital.uca.edu.ar/repositorio/revistas/estrategias-enfrentardiscriminacion-laboral.pdf

Varesi, G (2011). Argentina 2002-2011: neodesarrollismo y radicalización progresista. Realidad Económica 264, 33-59. Buenos Aires: IADE.Recuperado de https://periferiaactiva.files.wordpress.com/ 2014/07/varesi-g-argentina-2002-2011-neodesarrollismo-yradicalizacic3b3n-progresista.pdf

Yoguel, G. (1998). El ajuste empresarial frente a la apertura: la heterogeneidad de las respuestas de las PyMEs. Desarrollo Económico 38(volumen especial) 177-198.DOI: 10.2307/3467439

Recibido: 15.03.17

Aceptado: 15.04.17 